\title{
Proposal of new oxidation kinetics for sponge base E110 cladding tubes material
}

\author{
Jakub Krejčí ${ }^{1, *}$, Věra Vrtílková ${ }^{2}$, Pavel Gajdoš ${ }^{2}$, and David Rada ${ }^{2}$ \\ ${ }^{1}$ CTU in Prague, Faculty of Nuclear Sciences and Physical Engineering, V Holešovičkách 2, 18000 Praha 8, Czech Republic \\ ${ }^{2}$ UJP PRAHA a.s., Nad Kamínkou 1345, 15610 Praha - Zbraslav, Czech Republic
}

Received: 21 September 2015 / Received in final form: 7 January 2016 / Accepted: 17 May 2017

\begin{abstract}
Study of high temperature steam oxidation kinetics during the high temperature oxidation was carried out on the sponge base E1 10 cladding tubes material in the temperature range $600-1300{ }^{\circ} \mathrm{C}$. The oxidation kinetics derived from the weight gain measurements showed a parabolic rate law for temperatures $1100^{\circ} \mathrm{C}$ and higher only. For lower temperatures in range $800-1050^{\circ} \mathrm{C}$ especially, the parabolic law leads to very conservative prediction. Therefore, the new oxidation kinetics, different from the parabolic law, was designed. The experimental database containing more than 800 data points was compared with the new developed UJP-correlation and available correlations for E110 and Zircaloy alloys. Statistical analysis for all tested correlations was provided.
\end{abstract}

\section{Introduction}

Zirconium-based alloys are widely used for nuclear reactor components such as fuel claddings, grid spacers and guide tubes. These alloys combine low neutron absorption behaviour and good mechanical and corrosion properties under operating conditions. However, rapid oxidation of the fuel cladding occurs under loss of coolant accident (LOCA) conditions due to the zirconium-steam reaction. The oxidation is accompanied by intensive hydrogen production. The oxidation causes the mechanical deterioration and the embrittlement of the cladding. Nevertheless, the oxidation correlations of most computer codes simulating accident scenarios today mainly rely on Zircaloy-4 data. It is noted that almost all the computer codes in current use assume a parabolic kinetic law, i.e. mass gain is proportional to the square root of time.

In VVER nuclear reactors, the niobium-bearing alloy E110 $(\mathrm{Zr} 1 \% \mathrm{Nb})$ is used for cladding and structure materials. This material has been extensively investigated too, mainly in Russian and Eastern European laboratories, but the publicly available data are scarce (Böhmert et al. [1]; Yegorova et al. [2]; Bibilashvili et al. [3]).

Comparative studies show superior resistance to oxidation of either E110 or Zry-4 depending on test conditions, especially on temperature and atmosphere. Recently, numerous separate effects tests on high-temperature oxidation of various cladding alloys, including E110

\footnotetext{
* e-mail: krejci@ujp.cz
}

and Zry-4, in different atmospheres have been conducted (Grosse [4]; Steinbrück et al. [5]; Hozer et al. [6]) in Germany and Hungary.

In the past years, several experimental series have been performed at the UJP PRAHA, a.s. (UJP) with E110 sponge based cladding alloy. The aims of these experiments were to study and to compare the mechanical properties of the cladding materials and to investigate the effect of pure steam oxidation and hydrogen uptake on the mechanical performance of the claddings.

The objective of this study is to establish the rate law for steam oxidation kinetics of E110 sponge based alloy in the temperature range $600-1300^{\circ} \mathrm{C}$, which can be useful for LOCA analysis. This paper presents the results of the study of steam oxidation kinetics of E110 sponge based alloy in the above temperature range. The comparison of experimental data and several current use correlations based on E110 and Zircaloy alloys is also provided.

\section{Experimental}

All samples examined in this study were fabricated of the modified E110 alloys with improved oxidation properties (fabricated from $\mathrm{Zr}$ sponge). The chemical composition is presented in Table 1 . The tested tubular specimens had the following dimensions: outside diameter $9.1 \mathrm{~mm}$ and wall thickness $\sim 686 \mu \mathrm{m}$. Thirty or $45 \mathrm{~mm}$ long non-irradiated segments were cleaned, degreased, and then weighed. After the preparation procedure the specimens were exposed to steam $(0.1 \mathrm{MPa})$ at constant temperature $\left(600-1300^{\circ} \mathrm{C}\right)$ for variable time interval $(0-480 \mathrm{~min}$ depending on the temperature) in a resistance furnace. Tests were conducted 


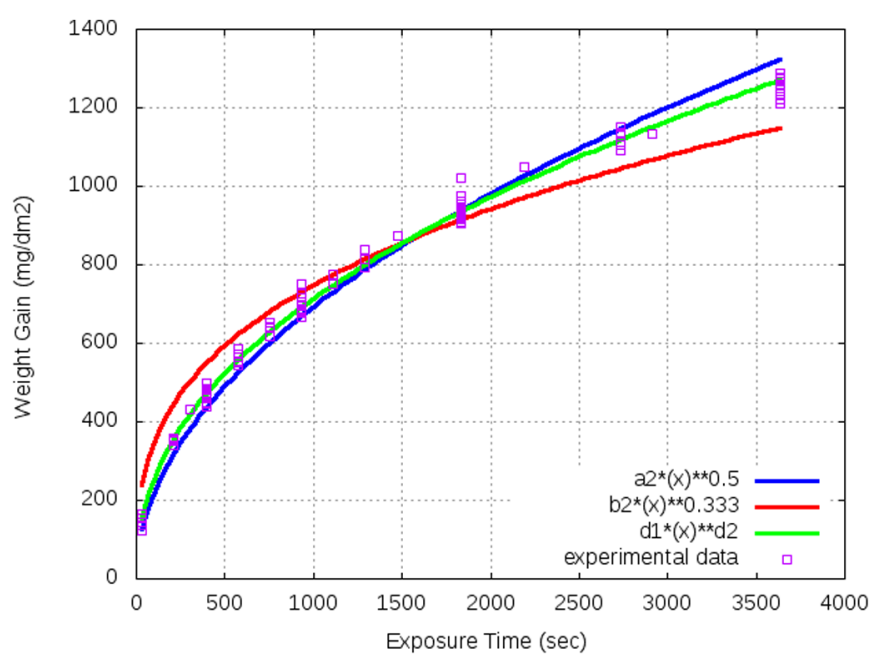

Fig. 1. Optimal oxidation kinetics (quadratic, cubic, and powerlaw function) for temperature $1050{ }^{\circ} \mathrm{C}$ and maximal exposure time 60 min.

Table 1. The chemical composition of the studied materials.

\begin{tabular}{lllll}
\hline wt.\% & $\mathrm{Nb}$ & $\mathrm{O}$ & $\mathrm{Fe}$ & $\mathrm{Zr}$ \\
\hline $\mathrm{Zr} 1 \mathrm{Nb}$ & 1.0 & $<0.1$ & $<0.05$ & Balanced \\
\hline
\end{tabular}

with average steam flow rates of $0.61 \mathrm{~g} / \mathrm{cm}^{2} / \mathrm{min}$ (deduced from water consumption). A single sample was exposed at a time. The oxidation was double-sided. The sample temperature was measured by a thermocouple placed inside the tube. After the high-temperature oxidation, the samples were quenched in ice water and dried out at $80^{\circ} \mathrm{C}$, and then weighed. Oxidation procedures were carried out with no applied stress.

\subsection{Oxidation kinetics}

\subsubsection{Development of new oxidation model}

Based on weight gain of exposed samples, a new model was developed. More than 800 experimental points were evaluated. For each temperature in the range $600-1300^{\circ} \mathrm{C}$, optimal power-law functions were set in the form (Fig. 1)

$$
W G=k t^{n} .
$$

The coefficients $k$ and $n$ based on interpolation (least square method) for some temperatures also depend on the maximal considered exposure time, as shown in Figure 2. It may by possible that the kinetics is changing during the oxidation process.

The optimal oxidation kinetics for temperatures $1100{ }^{\circ} \mathrm{C}$ and higher was close to quadratic, but for lower temperatures, the quadratic law do not fit experimental data well. Therefore, it was necessary to modify the " $n$-parameter". The found values were within the range of quadratic and cubic kinetics, which is typical for oxidation during normal operating parameters. It was possible to interpolate the optimal " $k$-parameter" via Arrhenius equation
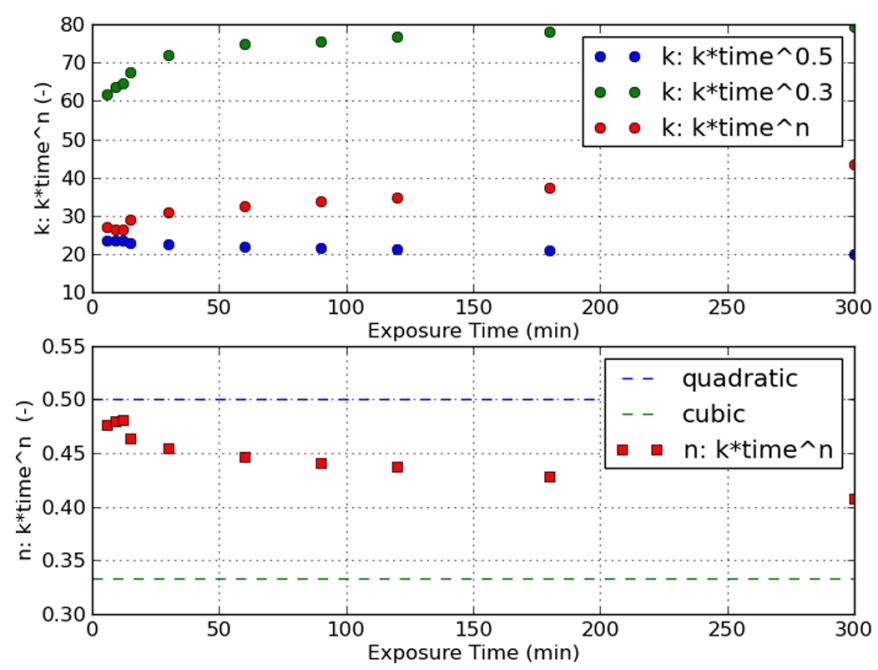

Fig. 2. Optimal oxidation kinetics (quadratic, cubic, and powerlaw function) for each maximal exposure time value, temperature $1050^{\circ} \mathrm{C}$.

$$
k=A \exp (-E / T) .
$$

It was necessary to divide the entire range of temperatures $600-1300^{\circ} \mathrm{C}$ into four sub-regions to maintain the accuracy. For having "continuous" curves, it was necessary to have different temperatures domains for " $n$ " and " $k$ ". Used regions approximately correspond to the physical processes in material (formation of $\beta$ phase and monoclinic to tetragonal oxide transformation [7]). The new oxidation kinetics model (UJP-correlation) was proposed at the following form (1). Using value $n=0.4$ below $768.4^{\circ} \mathrm{C}$ gives good results (experiment vs. calculation) and it was possible to use Arrhenius equation for " $k$ " in region 600 $934^{\circ} \mathrm{C}$ (Fig. 3).

$$
\begin{aligned}
n= & 0.4 \quad 600{ }^{\circ} \mathrm{C}<T<768.4^{\circ} \mathrm{C}, \\
n= & 2.609-4.898 \times 10^{-3}(T-273.15) \\
& +2.633 \times 10^{-6}(T-273.15)^{2} \\
& 768.4^{\circ} \mathrm{C}<T<960.3^{\circ} \mathrm{C} \\
n= & 1.202 \times 10^{-3}(T-273.15)-0.8208 \\
& 960.3^{\circ} \mathrm{C}<T<1098.9^{\circ} \mathrm{C}, \\
n= & 0.5 \quad 1098.9{ }^{\circ} \mathrm{C}<T<1300^{\circ} \mathrm{C}, \\
k= & 85265.6 \exp (-9875.59 / T) \\
& 600{ }^{\circ} \mathrm{C}<T<934.1^{\circ} \mathrm{C} \\
k= & 1072.21 \exp (-4592.60 / T) \\
& 934.1^{\circ} \mathrm{C}<T<1054.5^{\circ} \mathrm{C}, \\
k= & 33.33 \quad 1054.5^{\circ} \mathrm{C}<T<1098^{\circ} \mathrm{C}, \\
k= & 96482.3 \exp (-10913.1 / T) \\
& 1098^{\circ} \mathrm{C}<T<1300^{\circ} \mathrm{C} .
\end{aligned}
$$

\subsection{Comparison of experimental data and UJP- correlation}

Calculated values and experimental data comparison are provided in Figure 4. Almost all values predicted with the new oxidation model had absolute error lower than $10 \%$. 


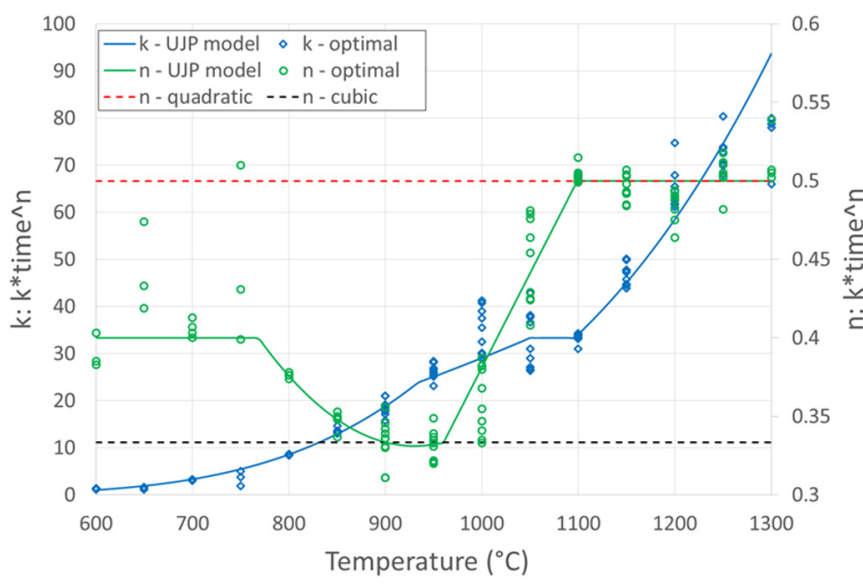

Fig. 3. Optimal coefficients $k$ and $n$ for each temperatures and maximal consider exposure time and the new oxidation kinetics model.

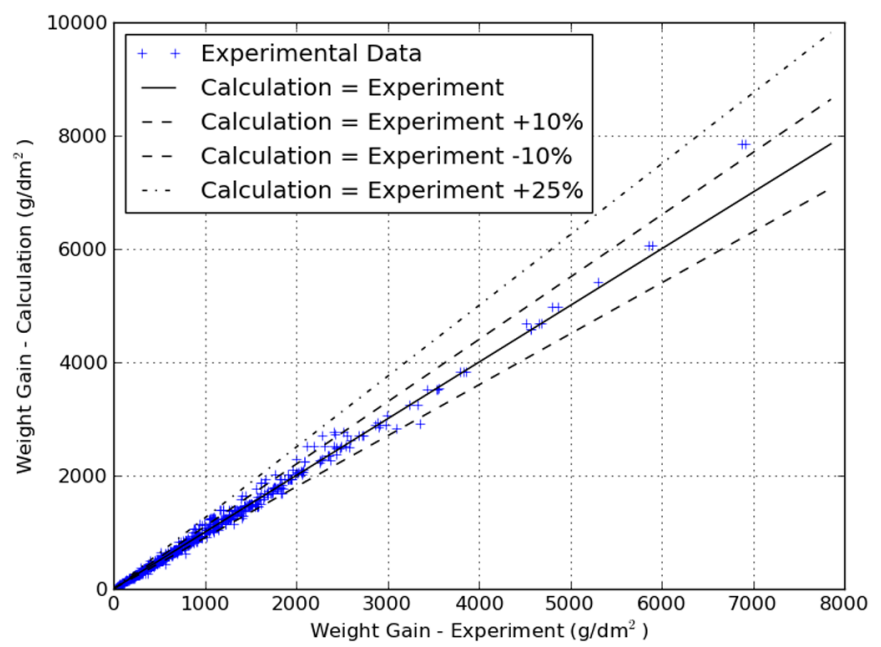

Fig. 4. Weight gain, comparison of experimental and UJPcorrelation data.

Definition of following properties describing relative error of calculating an experimental weight gain was used for statistical evaluation:

$$
\begin{gathered}
R=\frac{W G_{C A L C}}{W G_{E X P}}, \\
\bar{\sigma}=(R-\bar{R})^{2}, \\
\Delta_{\text {corr }}=\bar{R}-1+k_{95 / 95} \times \bar{\sigma},
\end{gathered}
$$

where $\bar{R}$ was the arithmetical average of $R$ values and $\sigma$ standard deviation. $\Delta_{\text {corr }}$ was correlation error, where $k_{95 / 95}$ was distribution factor corresponding to one-sided interval $95 \%$ at confidential probability $95 \%$ (for normal distribution law and large number of data points $\left.k_{95 / 95} \sim 1.645\right)$. After excluding the most extreme values (approx. $1 \%$ of all gathered data) a statistical evaluation for a total of 819 points was done. The arithmetical average $\bar{R}=1.003$, $\operatorname{median}_{R}=0.998$, standard deviation $\bar{\sigma}=6.2 \%$, and correlation error $\Delta_{\text {corr }}=0.109$ were obtained.
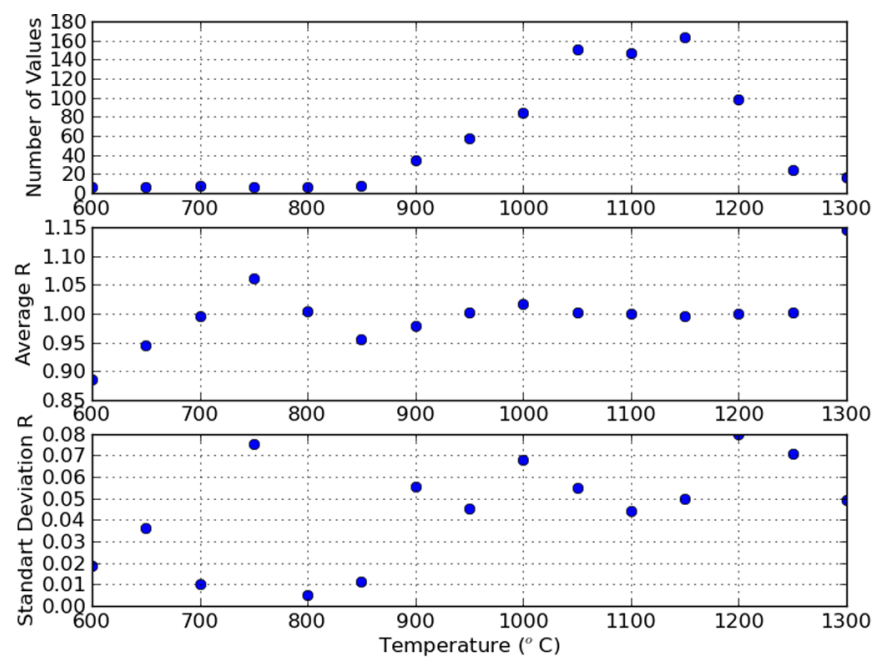

Fig. 5. Comparison of experimental and UJP-correlation data for each evaluated temperatures. Number of points, $R$-average, $R$ standard deviation.

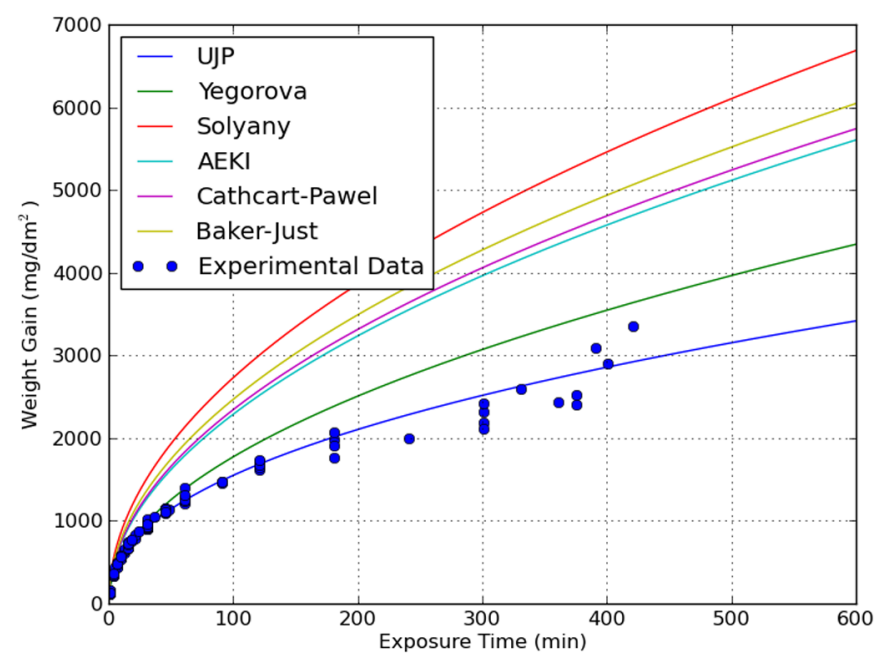

Fig. 6. Comparison of experimental data with several correlations, temperature $1050{ }^{\circ} \mathrm{C}$.

Values of $\bar{R}$ and for each temperature are summarized in Figure 5. It is evident that the calculated and experimental values are in very good agreement in the entire temperature range.

Low non-conservativism of prediction $(\sim 10 \%)$ was observed for temperature 600 and $650{ }^{\circ} \mathrm{C}$. Absolute values of mass gain (calculated minus experimental value) were very low (about $10 \mathrm{mg} / \mathrm{dm}^{2}$ ); therefore, this non-conservativism is not important.

\subsection{Comparison of experimental data and existing models}

The presented experimental data points were compared with existing correlation models also. Evaluation was performed for correlations based on E110 alloys Yegorova [2], Solyany [8], AEKI [9], and for Zircaloy based correlations Cathcart-Pawel [10] and Baker-Just [11] also. Very high degree of conservatism for all existing models in 

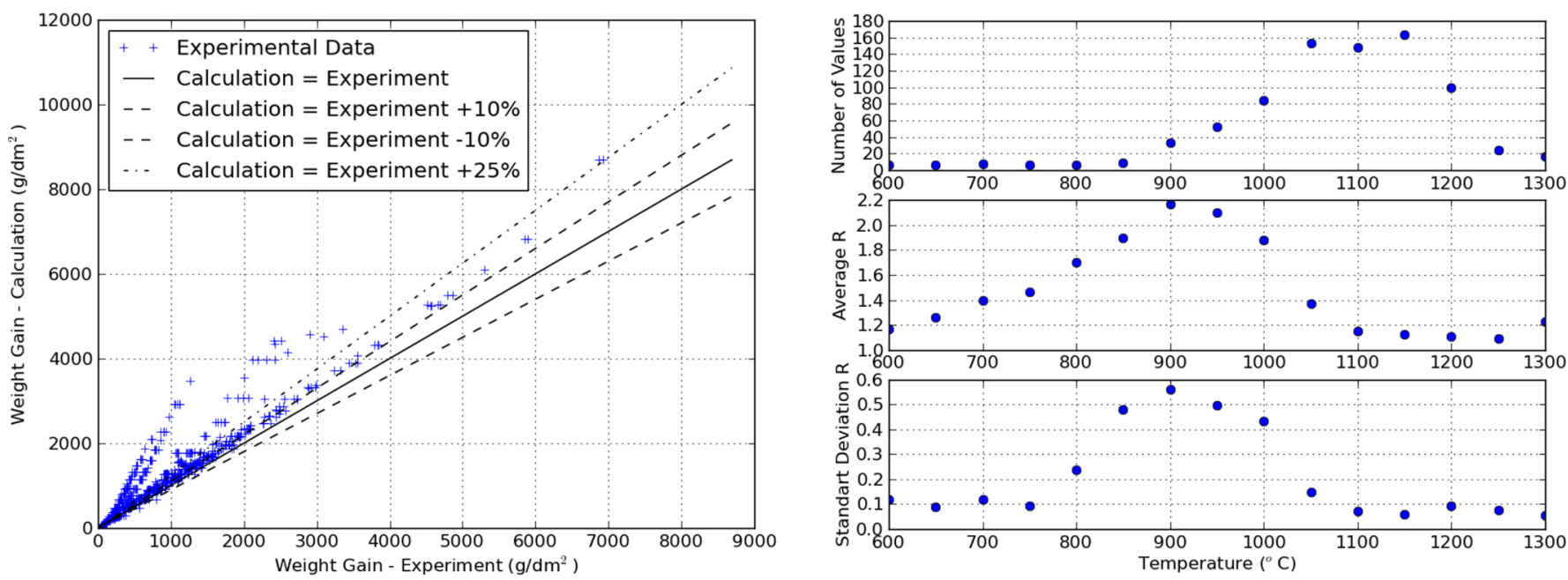

Fig. 7. Comparison of experimental and AEKI correlation data. Weight gain for all data (left) and $R$-parameter for each evaluated temperatures (right).
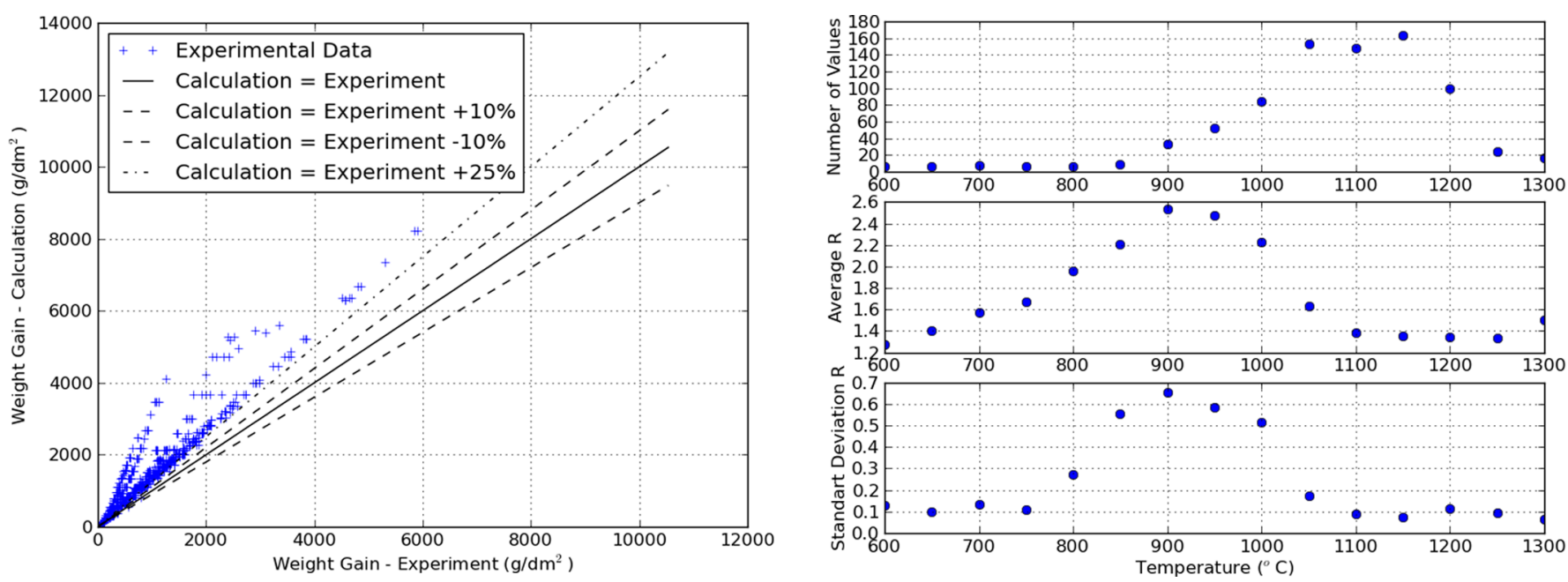

Fig. 8. Comparison of experimental and Solyany correlation data. Weight gain for all data (left) and $R$-parameter for each evaluated temperatures (right).
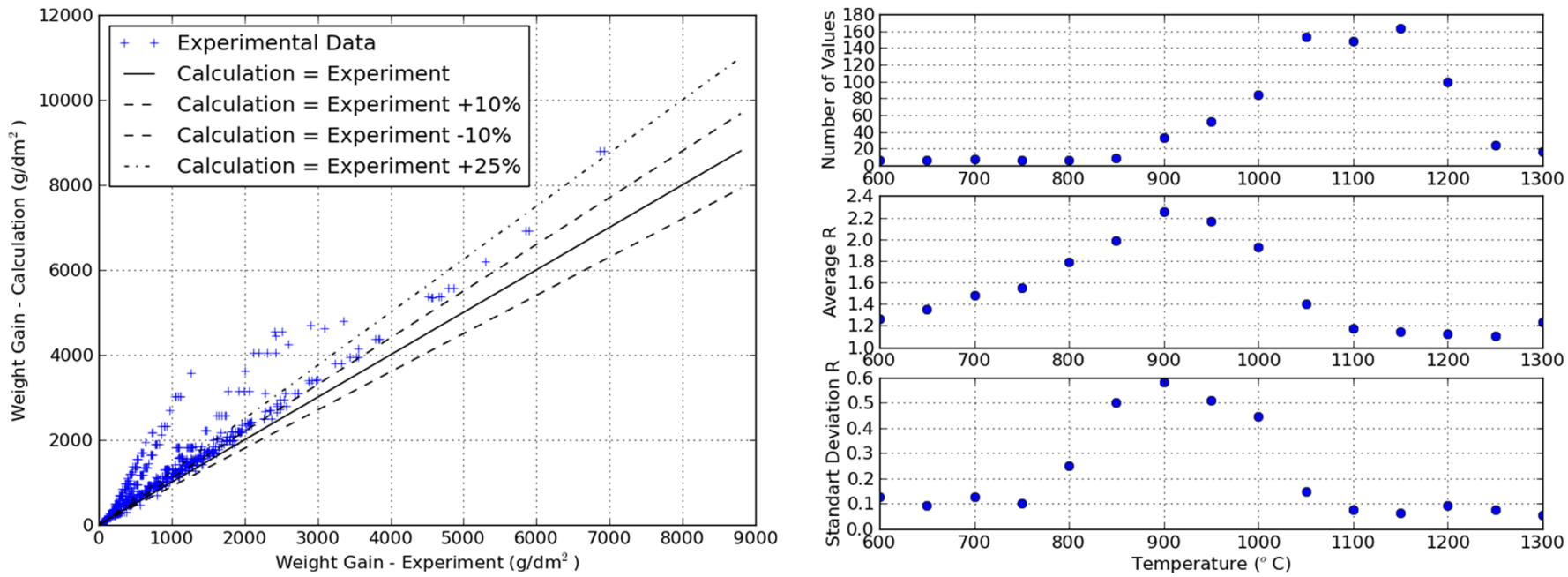

Fig. 9. Comparison of experimental and Cathcart-Pawel correlation data. Weight gain for all data (left) and $R$-parameter for each evaluated temperatures (right). 

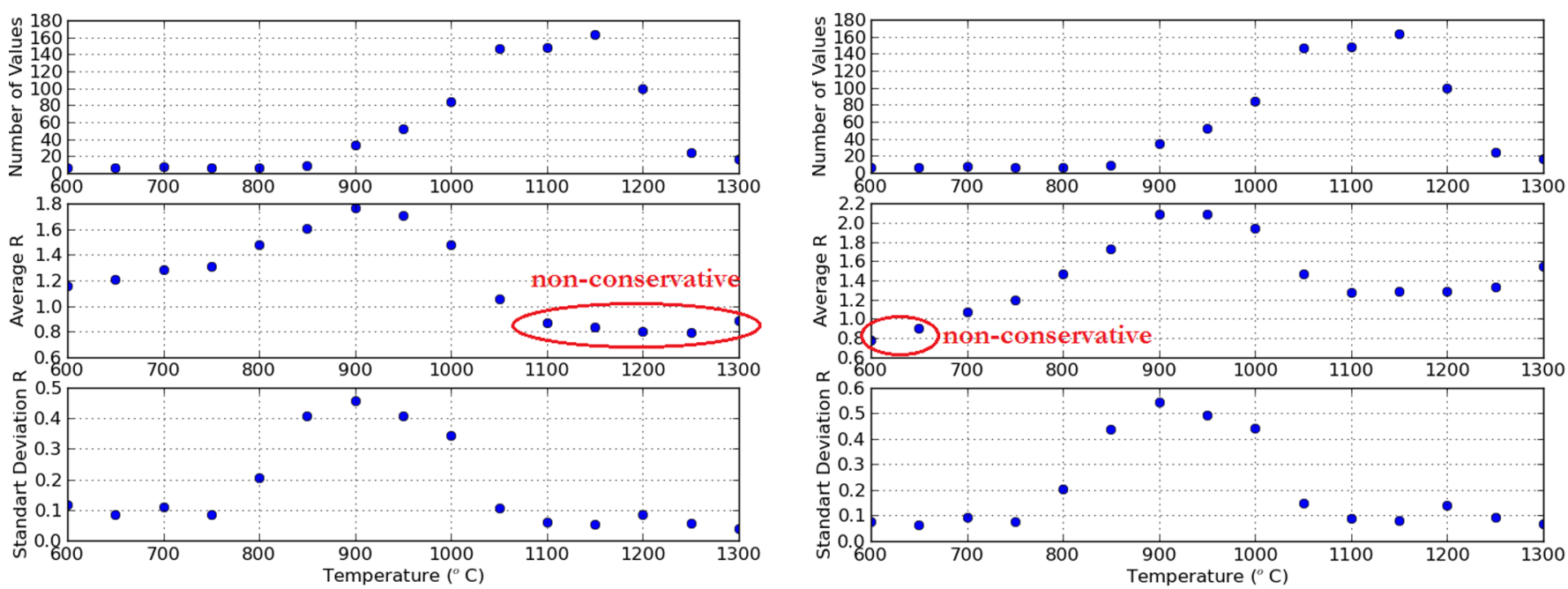

Fig. 10. Comparison of experimental and correlation data. $R$-parameter for each evaluated temperatures, Yegorova (left), Baker-Just (right).

temperature range $800-1050{ }^{\circ} \mathrm{C}$ is evident from Figures 6 10. Prediction in this region is higher by about $120 \%$ (for AEKI and Cathcart-Pawel), while for temperatures $1100{ }^{\circ} \mathrm{C}$ and more, it is higher only by about $10-20 \%$ (for AEKI and Cathcart-Pawel) and by about 40\% (for Solyany and Baker-Just). Prediction by about $20 \%$ higher can be accepted as low conservative and satisfactory. Only correlations Yegorova and Baker-Just provided nonconservative results for temperatures above $1050^{\circ} \mathrm{C}$ (Yegorova $\sim 20 \%$ ) and below $700^{\circ} \mathrm{C}$ (Baker-Just 10$20 \%$ ) respectively, see in Figure 10.

Baker-Just correlation is known to be always (too) conservative; therefore, the commentary to non-conservativism at low temperatures is appropriate. The Baker-Just correlation was developed for Zircaloy and temperatures $1000^{\circ} \mathrm{C}$ and higher only [11]. A discussion of extrapolation to lower temperature is provided in [12]. The slightly different behaviours for Zircaloy and E110 can be expected for low temperatures also.

The Yegorova correlation was developed for a temperature range between 800 to $1200{ }^{\circ} \mathrm{C}$. The most of the experimental points were measured at the temperature of $1100{ }^{\circ} \mathrm{C}$. The parabolic law is used in the whole temperature range and the experimental data were fitted with one Arrhenius equation. This approach probably led to non-conservativism of the correlation for temperatures above $1050{ }^{\circ} \mathrm{C}$.

\section{Conclusions}

The presented paper was concerned with the measurement of the oxygen weight gain in the E110 cladding tubes after high-temperature oxidation. The main goal was to develop a new model for oxidation kinetics and compare experimental data with existing correlations. The following conclusions can be drawn:

- The results of the oxygen weight gain measurements showed that the oxidation kinetics is not quadratic in the entire range of temperatures $600-1300{ }^{\circ} \mathrm{C}$ for $\mathrm{E} 110$ sponge based alloys. Quadratic law is applicable only for temperatures $1100^{\circ} \mathrm{C}$ and higher. Changes of oxidation kinetics parameters with time for temperatures 1000 and 1050 were observed also.

- A new oxidation UJP model for sponge based E110 alloys was proposed. It was designed based on more than 800 experimental points and it is suitable for the temperature range $600-1300^{\circ} \mathrm{C}$. Statistical evaluation was provided and the correlation error was specified $\left(\Delta_{\text {corr }}=0.109\right)$.

- Several available correlations for E110 and Zircaloy alloys were compared with experimental results also. It was shown that results for temperatures above $1100^{\circ} \mathrm{C}$ provided satisfactory agreement. Very conservative results were estimated for lower temperatures, especially for $800-1050{ }^{\circ} \mathrm{C}$ range, which is important for LOCA conditions. The low non-conservativism for Baker-Just correlation within low temperatures and Yegorova for temperatures above $1050{ }^{\circ} \mathrm{C}$ was observed and discussed. - The UJP model is available for use in transient fuel codes.

Further investigation will be focused on the influence of pre-oxidation and pre-hybridization of samples. It will provide more reliable results for the fuel claddings within operation.

Financial support of this research through the grants no. SGS14/ 156/OHK4/2T/14, "TA02011025, program ALFA - TAČR", CZ.2.16/3.1.00/21563, and ČEZ a.s. company is gratefully acknowledged.

\section{References}

1. J. Böhmert, M. Dietrich, J. Linek, Comparative studies on high-temperature corrosion of $\mathrm{Zr}-1 \% \mathrm{Nb}$ and Zircaloy-4, Nucl. Eng. Des. 147, 53 (1993)

2. L. Yegorova, K. Lioutov, N. Jouravkova, A. Knobeev, V. Smirnov, V. Chesanov, A. Goryachev, Experimental study of embrittlement of $\mathrm{Zr}-1 \% \mathrm{Nb}$ VVER cladding under LOCA-Relevant conditions, NUREG/IA-0211, IRSN 2005194, March 2005 
3. Y.K. Bibilashvili, N.B. Sokolov, L.N. Andreyeva-Andrievskaya, A.V. Salatov, High temperature interaction of fuel rod cladding material (Zr1\% Nb alloy) with oxygen-containing mediums, IAEA-TEDOC-921 (IAEA, 1995)

4. M. Grosse, Comparison of the high-temperature steam oxidation kinetics of advanced cladding materials, Nucl. Technol. 170, 272 (2010)

5. M. Steinbruck, J. Borchley, A.V. Goryachev, M. Grosse, T.J. Haste, Z. Hozer, A.E. Kisselev, V.I. Nalivaev, V.P. Semishkin, L. Sepold, J. Stuckert, N. Ver, M.S. Veshchunov, Status of studies on high-temperature oxidation and quench behaviour of zircaloy-4 and E110 cladding alloys, presented at 3rd European Rev. Mtg. Severe Accident Research (ERMSAR-2008), Nessebar, Bulgaria (2008)

6. Z. Hozér, E. Perez-Fero, T. Novotny, I. Nagy, M. Horváth, A. Pintér-Csirdás, A. Vimi, M. Kunstár, T. Kemény, Experimental comparison of the behavior of E110 and E110G claddings at high temperature, in Zirconium in the nuclear industry: 17th International Symposium, STP 1543 (2015), pp. 932-951

7. J. Sopoušek, Phase diagrams selected alloys based on system $\mathrm{Zr}-\mathrm{Nb}-\mathrm{Fe}-\mathrm{O}-\mathrm{H}$, Research report, in Czech language, Brno, 2015
8. V.I. Solyany, Yu.K. Bibilashvili, V.Yu. Tonkov, High temperature oxidation and deformation of $\mathrm{Zr} 1 \% \mathrm{Nb}$ alloy of VVER fuels, in Proceedings, OECD-NEA-CSNI/IAEA Specialists' Meeting on Water Reactor Fuel Safety and Fission Product Release in Off-Normal and Accident Conditions, Riso, Denmark, 16-20 May 1983 (1983), p. 163

9. P. Van Uffelen, C. Gyori, A. Schubert, J. van de Laar, Z. Hózer, G. Spykman, Extending the application range of a fuel performance code from normal to operating to design basis accident conditions, J. Nucl. Mater. 383, 137 (2008)

10. J.V. Cathcart, Quarterly Progress Report on the Zirconium Metal-Water Oxidation Kinetics Program Sponsored by the NRC Division of Reactor Safety Research for April-June 1976, ORNL/NUREG/TM-41 (Oak Ridge National Laboratory, 1976)

11. L. Baker, L.C. Just, Studies of metal-water reactions at high temperatures (Argonne National Laboratory, ANL-6548, 1962)

12. S. Leistikow, G. Schanz, High temperature oxidation of zircaloy-4 cladding tubes in steam $\left(600-1600{ }^{\circ} \mathrm{C}\right)$, in 9th International Congress on Metallic Corrosion, Toronto, Canada, 3-7 June 1984 (1984), pp. 282-287

Cite this article as: Jakub Krejčí, Věra Vrtílková, Pavel Gajdoš, David Rada, Proposal of new oxidation kinetics for sponge base E110 cladding tubes material, EPJ Nuclear Sci. Technol. 3, 18 (2017) 